\title{
Article \\ Sustainable Adsorption Method for the Remediation of Crystal Violet Dye Using Nutraceutical Industrial Fenugreek Seed Spent
}

\author{
Syed Noeman Taqui ${ }^{1}$, Mohan C.S. ${ }^{2}$, Mohammad Shahab Goodarzi ${ }^{3}{ }^{(0)}$, Mohamed Abdelghany Elkotb ${ }^{4,5}{ }^{(1)}$, \\ Bibi Ahmadi Khatoon ${ }^{2}$, Manzoore Elahi M. Soudagar ${ }^{6}{ }^{(0)}$, Isa Baba Koki ${ }^{7}{ }^{(0)}$, Ashraf Elfasakhany ${ }^{8}$, \\ Amany Salah Khalifa ${ }^{9}$, Masood Ashraf Ali ${ }^{10}{ }^{\circ}$, Zaphar Saifullah ${ }^{6}$, Md Irfanul Haque Siddiqui ${ }^{11}(\mathbb{1}$,

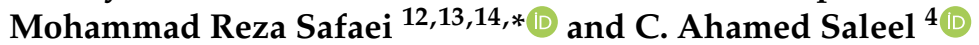

Citation: Taqui, S.N.; C.S., M.; Goodarzi, M.S.; Elkotb, M.A.; Khatoon, B.A.; Soudagar, M.E.M.; Koki, I.B.; Elfasakhany, A.; Khalifa, A.S.; Ali, M.A.; et al. Sustainable Adsorption Method for the Remediation of Crystal Violet Dye Using Nutraceutical Industrial Fenugreek Seed Spent. Appl. Sci. 2021, 11, 7635. https://doi.org/10.3390/ app11167635

Academic Editor: Monica Gallo

Received: 20 July 2021

Accepted: 17 August 2021

Published: 19 August 2021

Publisher's Note: MDPI stays neutral with regard to jurisdictional claims in published maps and institutional affiliations.

Copyright: (c) 2021 by the authors. Licensee MDPI, Basel, Switzerland. This article is an open access article distributed under the terms and conditions of the Creative Commons Attribution (CC BY) license (https:/ / creativecommons.org/licenses/by/ $4.0 /)$.
1 CSIR—Central Food Technological Research Institute, Mysore 570020, Karnataka, India; noemansyed89@gmail.com

2 Department of Chemistry, Yuvaraja's College (Autonomous), University of Mysore, Mysuru 570005, Karnataka, India; mohan0785@yahoo.com (M.C.S.); bibiahmadikhatoon@gmail.com (B.A.K.)

3 Institute of Research and Development, Duy Tan University, Da Nang 550000, Vietnam; mohammadshahabgoodarzi@duytan.edu.vn

4 Mechanical Engineering Department, College of Engineering, King Khalid University, P.O. Box 394, Abha 61421, Saudi Arabia; melkotb@kku.edu.sa or mkotb@eng.kfs.edu.eg (M.A.E.); ahamedsaleel@gmail.com (C.A.S.)

5 Mechanical Engineering Department, Faculty of Engineering, Kafrelsheikh University, Kafrelsheikh 33516, Egypt

6 Department of Mechanical Engineering, School of Technology, Glocal University, Delhi-Yamunotri Marg, SH-57, Mirzapur Pole, Saharanpur District 247121, Uttar Pradesh, India; me.soudagar@gmail.com (M.E.M.S.); Saifullah@theglocaluniversity.in (Z.S.)

7 Department of Chemistry, Yusuf Maitama Sule University, PMB 3220 Kano, Nigeria; isakoki@yahoo.com

8 Mechanical Engineering Department, College of Engineering, Taif University, P.O. Box 11099, Taif 21944, Saudi Arabia; a.taha@tu.edu.sa or ashr12000@yahoo.com

9 Department of Clinical Pathology and Pharmaceutics, College of Pharmacy, Taif University, P.O. Box 11099, Taif 21944, Saudi Arabia; dr.amani.s@tu.edu.sa

10 Department of Mechanical Engineering, College of Engineering, Prince Sattam Bin Abdulaziz University, Al Kharj 16273, Saudi Arabia; mas.ali@psau.edu.sa

11 Department of Mechanical Engineering, College of Engineering, King Saud University, Riyadh 11451, Saudi Arabia; msiddiqui2.c@ksu.edu.sa

12 Mechanical Engineering Department, Faculty of Engineering, King Abdulaziz University, Jeddah 21589, Saudi Arabia

13 Department of Medical Research, China Medical University Hospital, China Medical University, Taichung 40402, Taiwan

14 Department of Mechanical Engineering, Florida International University, Miami, FL 33174, USA

* Correspondence: msafaei@fiu.edu or cfd_safaei@yahoo.com; Tel.: +1-502-657-9981

Abstract: Nutraceutical industrial fenugreek seed spent (NIFGS), a relatively low-cost material abundantly available with little toxicity is used in crystal violet (CV) dye remediation from aqueous media and reported in the present study. To access the adsorption capacity, the factors affecting it are kinetics and the equilibrium thermodynamics. All the experiments were designed at approximately $\mathrm{pH}$ 7. The adsorption isotherm model proposed by Langmuir fits better than the Freundlich isotherm model. Kinetic studies data confirm the pseudo-second order model. It is evident from thermodynamic parameter values that the process of adsorption is endothermic, physical and dynamic. The process optimization of independent variables that influence adsorption was carried out using response surface methodology (RSM) through bi-level fractional factorial experimental design (FEED). The analysis of variance (ANOVA) was implemented to investigate the combined effect of parameters influencing adsorption. The possibilities of using dye-adsorbed NIFGS ("sludge") for the fabrication of the composites using plastic waste are suggested. 
Keywords: nutraceutical industrial fenugreek seed spent; crystal violet; adsorption studies; fractional factorial experimental design; analysis of variance

\section{Introduction}

The Indian clothing and textile sector ranks second in the world. This sector has two divisions, manufacturing and agricultural related activities. The former employs over 35 million people and contributes 3\% GDP; while the latter engages over 60 million workforces and adds $14 \%$ towards industrial production. These activities contribute to $3 \%$ GDP and about $14 \%$ towards industrial production [1]. The textile manufacturing sector is broadly classified into organized and unorganized sectors. The unorganized sector operates in small units and adopts traditional tools, techniques and outdated technologies which results in the release of large amounts of toxic and hazardous dyes into the environment [2]. Thus, the textile industries have a dubious distinction of being one amongst the top ten industries causing pollution [3].

An immediate challenge the textile industry faces is to attain sustainability by reducing carbon and water footprints [4], diminishing the colour and reducing ecological and public health problems [5]. The major causes of pollution from textile industries are low profit margins, the lack of cost-effective technologies, over-capacity, severe competition, and strict environmental regulations in the treatment of wastewater. The dyes designed for textile industries are environmentally stable which poses the additional challenge of removing the toxic compounds from TIE using conventional technologies. Thus, removal of dyes and allied materials with minimum overhead charges from TIE assumes paramount importance.

The methods, procedures and techniques used for the remediation of dyes in TIE are broadly classified as biological, biological cum chemical, electrochemical, electrocoagulation, physical methods using UV radiations, photo-catalytic degradation [6,7] and the use of nanomaterial and activated carbons. Various related studies have been carried out pertaining to thermal engineering [8-16], photocatalysis [17,18], supercapacitor [19] and sonocatalytic degradation [20]. All the methods and materials have serious limitations, such as the disposal of residual sludge, the high cost of plant establishment, increased operation cost, interference by wastewater ingredients, the problem of regeneration, secondary pollutants and sensitivity to changes in the wastewater input $[21,22]$.

Currently, the adsorption technique with the characteristics of simplicity, efficiency, minimum discharge of toxic by-products and possibilities of scaling up to field-level is widely employed for the remediation of TIE. The pore structure, cost, abundant availability and ready-to-use adsorbent are the qualities required for enhancement of efficiency of the removal of toxic dyes from TIE. Most of the materials proposed as adsorbents do not qualify for the needs and demands of the textile industry. Scant literature available on the problem of sludge generated during the process poses an additional challenge. These limitations have created a surge amongst scientists to look for an alternative, which is economically feasible and environmentally acceptable.

Nutraceutical industries are growing rapidly with a possible profit and produces an unprecedented myriad of spent/waste. The nutraceutical industrial spent (NIS) produced as by-product has no feed, fuel or fertilizer value. Presently, NIS is disposed in landfills and as low-calorific value fuel which is attributed to the pore structure which traps moisture from the atmosphere. Incineration/burning of NIS results the formation of greenhouse gases which is environmental pollution and leaves a carbon footprint. Utilization of NIS as an adsorbent to amputate the toxic substances from TIE ecologically alleviates waste disposal problems and addresses the needs and demands of sustainability [23-25].

India ranks first by producing about $2.40 \times 105$ tons of fenugreek seed which is extensively used as nutraceutical [26]. Fenugreek (Trigonella foenum-graecum L.) is a nutraceutical belonging to the legume family. This is an annual crop native to the region stretching from Iran to northern India, but now it is widely cultivated in China, Ukraine, 
Greece, and North and East Africa [27]. We reported the use of NIFGS as an adsorbent in the extraction of blue acid 113, a bisazo acidic dye from water and TIE [28].

Crystal violet $(\mathrm{CV})$ dye belongs to the class of triarylmethane dyes. It is also called gentian violet, with the molecular formula $\mathrm{C}_{25} \mathrm{H}_{30} \mathrm{~N}_{3} \mathrm{Cl}$. CV is extensively utilized for the dyeing of leather, cotton, paper, silk and nylon [29]. Dye with a high molar extinction coefficient, 88,000 moles ${ }^{-1} \mathrm{~L}^{-1}$ when released into the hydrosphere may cause significant pollution due to its resistant nature, reducing rays of sunlight and causing the unwanted colour present in the water bodies, fighting against photochemical and biological problems in aquatic life. Thus, removal of CV from industrial effluents assumes paramount importance. The current article exemplifies the incorporation of NIFGS for adsorption of CV from aqueous solution and TIE. The study also suggests the implementation of dyeadsorbed NIFGS as a filler ingredient in composite material fabrication from waste plastic. The novelty of the research work is there is a scant literature on the CV dye remediation and NIFGS use as adsorbent. This study endeavours to explore the use of nutraceutical industrial fenugreek seed spent adsorbent for bioremediation of $\mathrm{CV}$. This poisonous dye used in textile industries is discharged as a pollutant.

\section{Experiment Details}

\subsection{Materials}

The dye used is crystal violet. It has a molecular weight of $407.98 \mathrm{~g} / \mathrm{mol}, \lambda_{\max }=590 \mathrm{~nm}$. The dye concentration is measured using an UV-vis spectrometer (Perkin-Elmer Lambda EZ-201, USA).

\subsection{Parametric Effect Study}

The experimental factors ( $\mathrm{pH}$ grade, dye initial concentration, dosage and temperature) influence was studied using batch experiments. For preparing a stock solution of CV (1000 mg L $\left.{ }^{-1}\right)$, double distilled water was used. Preparation of solution concentrations ranging from $25 \mathrm{mg} \mathrm{L}^{-1}$ to $300 \mathrm{mg} \mathrm{L}^{-1}$, was performed using the bulk stock solution. A $250 \mathrm{~mL}$ Erlenmeyer flask was combined with a dye solution dose of $50 \mathrm{~mL}$. The calculated quantity of NIFGS was added to every flask. Parametrical evaluations were performed for various parameter ranges stated, $\mathrm{pH}(2,4,6,7,8,10$ and 12); initial concentration of CV dye solution (25-300 $\left.\mathrm{mg} \mathrm{L}^{-1}\right)$ and adsorbent quantity (0.025-0.200 g) in $50 \mathrm{~mL}\left(0.500-4.000 \mathrm{~g} \mathrm{~L}^{-1}\right)$. Thermal influence on adsorption was investigated for a dye concentration of $200 \mathrm{mg} \mathrm{L}^{-1}$ at three selected temperatures. The data were fitted into Equations (1)-(3), observed in Table 1. Solution stirring at $165 \mathrm{rpm}$ was carried out for $3 \mathrm{~h}$ in an orbital shaker under constant thermal conditions. Samples were withdrawn at predetermined equilibrium time. The unadsorbed CV dye in the solution phase was separated from NIFGS by centrifugation with $3000 \mathrm{rpm}$ for five minutes. If the solution was unclear, the centrifugation was repeated for an additional $5 \mathrm{~min}$. The $\mathrm{CV}$ dye concentration at an equilibrium pertaining to the supernatant centrifuged solution was determined using a spectrophotometer. To study the effect in a range of $\mathrm{pH} 2-12$, batch experiments were performed. The $\mathrm{pH}$ regulation within a desired range was achieved by concentrating the solution with $0.01-1.00 \mathrm{M} \mathrm{HCl}$ or $\mathrm{NaOH}$ solution. For the adsorption kinetic studies of CV dye solution (200 $\left.\mathrm{mg} \mathrm{L}^{-1}\right)$, three temperatures $(303,313$ and $323 \mathrm{~K})$ were selected, and experiments carried out with time as independent variables. Experiments were replicated thrice, and the mean values were considered.

\subsection{Characterization Methods}

IR spectra were recorded using the FTIR spectrophotometer (Perkin Elmer 3 lambda). The JEOL model 3300 scanning electron microscope was used to record SEM images. A pH meter Model 802, Systronics, India, was used to measure $\mathrm{pH}$. 
Table 1. Mathematical equations used in the manuscript and their significance.

\begin{tabular}{|c|c|c|c|}
\hline Eq. No. & Equation & Description & Parameter \\
\hline \multicolumn{4}{|c|}{ General Adsorption Studies } \\
\hline (1) & $q_{e}=\frac{\left(C_{o}-C_{e}\right) V}{W}$ & $\begin{array}{l}\text { Adsorption capacity at } \\
\text { equilibrium }\end{array}$ & \multirow{3}{*}{$\begin{array}{c}q_{e}: \text { equilibrium adsorption capacity }\left(\mathrm{mg} \mathrm{L}^{-1}\right) \\
q_{t} \text { : time } t \text { adsorption capacity }\left(\mathrm{mg} \mathrm{L}^{-1}\right) \\
C_{0}: \text { initial concentration of adsorbent }\left(\mathrm{mg} \mathrm{L}^{-1}\right) \\
C_{e}: \text { equilibrium adsorbent concentration }\left(\mathrm{mg} \mathrm{L}^{-1}\right) \\
C_{t}: \text { time } t \text { adsorbent concentration } \\
V: \text { adsorbate solution volume }(\mathrm{L}) \\
W: \text { adsorbent weight }(\mathrm{g})\end{array}$} \\
\hline (2) & $q_{t}=\frac{\left(C_{o}-C_{t}\right) V}{W}$ & Adsorption capacity at time $t$ & \\
\hline (3) & $R E \%=\left[\frac{C_{o}-C_{e}}{C_{o}}\right] * 100$ & $\begin{array}{l}\text { Percentage removal efficiency } \\
\qquad(R E)\end{array}$ & \\
\hline \multicolumn{4}{|c|}{ Adsorption isotherm studies } \\
\hline$(4)$ & $q_{e}=\frac{Q_{m} K_{a} C_{e}}{1+K_{a} C_{e}}$ & Langmuir isotherm [30] & \multirow{2}{*}{$\begin{array}{c}Q_{m}: \text { monolayer adsorption capacity }\left(\mathrm{mg} \mathrm{g}^{-1}\right) \\
K_{a}: \text { adsorption constant of Langmuir isotherm } \\
\left(\mathrm{L} \mathrm{mg} \mathrm{mg}^{-1}\right) \\
R_{L} \text { factor implies whether the adsorption is when } \\
\left(R_{L}>1\right) \text { : unfavourable } \\
\left(R_{L}=1\right) \text { : linear } \\
\left(0<R_{L}<1\right) \text { : favourable and } \\
\left(R_{L}=0\right) \text { : irreversible }\end{array}$} \\
\hline (5) & $R_{L}=\frac{1}{1+K_{a} C_{0}}$ & $\begin{array}{l}\text { Separation factor of } \\
\text { Langmuir isotherm }\end{array}$ & \\
\hline (6) & $q_{e}=K_{F} C_{e}^{\frac{1}{n_{F}}}$ & Freundlich isotherm [31] & $\begin{array}{c}K_{F} \text { is adsorption constant of Freundlich isotherm } \\
(\mathrm{mg} / \mathrm{g}) \\
n_{F}: \text { heterogeneity factor indicates the nature of } \\
\text { adsorption is } \\
\left(n_{F}<1\right) \text { : chemisorption } \\
\left(n_{F}=1\right) \text { : linear or } \\
\left(n_{F}>1\right): \text { physisorption }\end{array}$ \\
\hline \multicolumn{4}{|c|}{ Adsorption kinetic studies } \\
\hline (7) & $q_{t}=q_{e}\left(1-e^{-k_{1} t}\right)$ & $\begin{array}{l}\text { Pseudo-first order } \\
\text { Equation [32] }\end{array}$ & \multirow{2}{*}{$\begin{array}{c}q_{t}: \text { time } t \text { adsorption capacity }\left(\mathrm{mg} \mathrm{L}^{-1}\right) \\
q_{e}: \text { equilibrium adsorption capacity }\left(\mathrm{mg} \mathrm{L}^{-1}\right) \\
k_{1}: \text { rate constant of pseudo-first order }\left(\mathrm{s}^{-1}\right) \\
k_{2}: \text { rate constant of pseudo-second order } \\
\left(\mathrm{mol}^{-1} \mathrm{~L}^{-1} \mathrm{~s}^{-1}\right) \\
t \text { : adsorption duration }(\mathrm{s})\end{array}$} \\
\hline$(8)$ & $q_{t}=\frac{q_{e}^{2} k_{2} t}{1+q_{e} k_{2} t}$ & $\begin{array}{l}\text { Pseudo-second order } \\
\text { Equation [33] }\end{array}$ & \\
\hline \multicolumn{4}{|c|}{ Adsorption thermodynamic studies } \\
\hline (9) & $\Delta G^{\circ}=\Delta H^{\circ}-\Delta S^{\circ} T$ & Standard Gibbs free energy & $\Delta G^{\circ}:$ standard free energy $\left(\mathrm{J} \mathrm{mol}^{-1}\right)$ \\
\hline$(10)$ & $\Delta G^{\circ}=-R T \ln K_{e q}$ & $\begin{array}{l}\text { Standard Gibbs free energy at } \\
\text { chemical equilibrium }\end{array}$ & $\begin{array}{c}\Delta H^{\circ}: \text { enthalpy change }\left(\mathrm{J} \mathrm{mol}^{-1}\right) \\
\Delta S^{\circ}: \text { entropy change }\left(\mathrm{J} \mathrm{mol}^{-1} \mathrm{~K}^{-1}\right) \\
\text { T: absolute temperature }(\mathrm{K})\end{array}$ \\
\hline$(11)$ & $K_{e q}=\frac{C_{o}}{C_{e}}$ & $\begin{array}{l}\text { Thermodynamic equilibrium } \\
\text { constant }\end{array}$ & $\begin{array}{l}\mathrm{R} \text { : ideal gas constant }\left(\mathrm{J} \mathrm{mol}^{-1} \mathrm{~K}^{-1}\right) \\
K_{\text {eq }} \text { : chemical equilibrium constant }\end{array}$ \\
\hline$(12)$ & $\ln K_{e q}=\frac{\Delta S^{\circ}}{R}-\frac{\Delta H^{\circ}}{R}$ & $\begin{array}{c}\text { Variant of standard Gibbs free } \\
\text { energy }\end{array}$ & $\begin{array}{c}C_{o} \text { : initial adsorbent concentration }\left(\mathrm{mg} \mathrm{L}^{-1}\right) \\
C_{e}: \text { adsorbent concentration at equilibrium }\left(\mathrm{mg} \mathrm{L}^{-1}\right)\end{array}$ \\
\hline
\end{tabular}

\subsection{Statistical Optimization of Process Parameters}

An experimental design [34] for the optimization of five process parameters at two levels was prepared for the CV-NIFGS system to obtain a quadratic regression equation using the ANOVA model.

\section{Experimental Outcomes}

\subsection{Analyses of SEM Images}

Figure $1 \mathrm{a}, \mathrm{b}$, illustrates the pictorial presentation of SEM images. The dye adsorption onto the NIFGS surface can be depicted from these pictures. The NIFGS surface texture has a porous and fibrous structure which resembles a honeycomb shape, it enhances the 
adsorption of the substrate (dye) on it. Figure 1a describes the structure of the pores which help to fasten the adsorption process, while Figure $1 \mathrm{~b}$ shows the limited filling of pores by the dye.

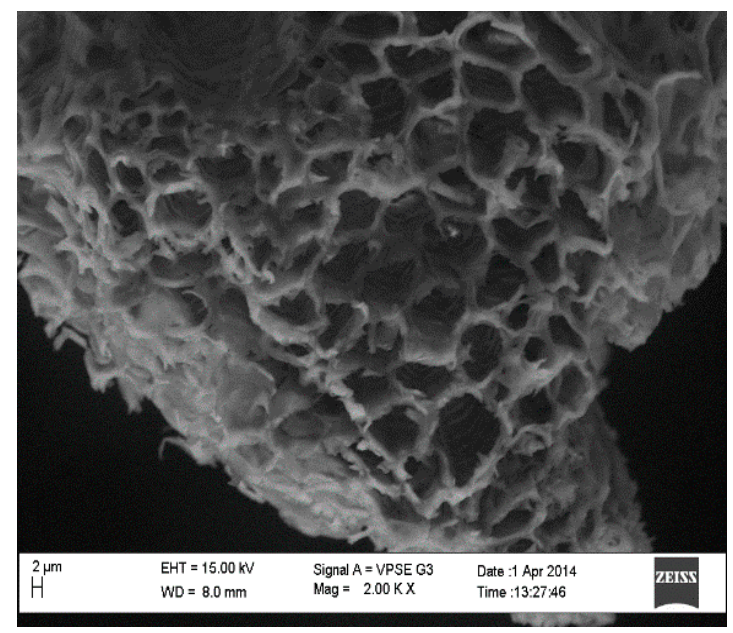

(a)

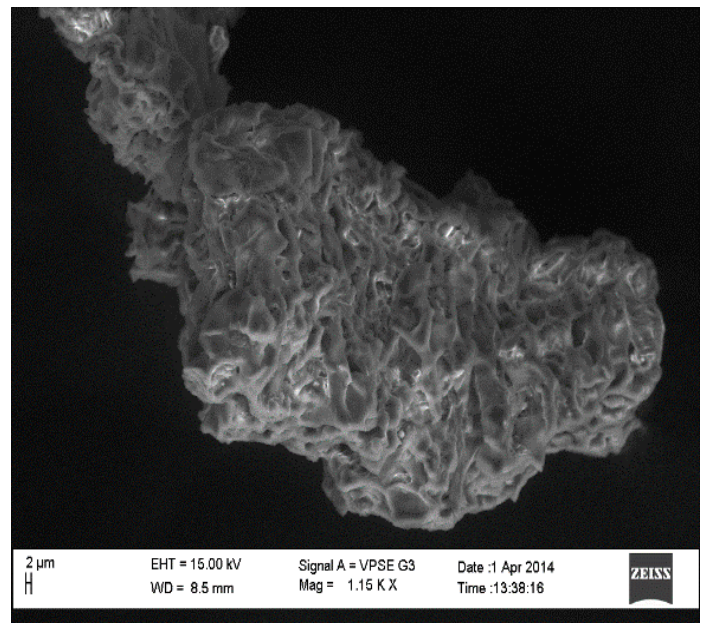

(b)

Figure 1. SEM images of (a) NIFGS and (b) CV-NIFGS.

\subsection{The Influence of Variables on CV Adsorption on NIFGS \\ 3.2.1. Solution $\mathrm{pH}$}

The adsorption capacity of NIFGS depends on solution $\mathrm{pH}$. The $\mathrm{pH}$ plays dual roles: first, to instigate surface characteristics of adsorbent and second, the chemical nature of solution [35]. The $\mathrm{pH}$ as a parameter, and assumes importance to substantiate the efficiency of the adsorbent under study. The knowledge of this parameter is significant when the process is scaled to commercial levels [36]. The NIFGS exhibits good capacity of adsorption with increased $\mathrm{pH}$. This characteristic is dedicated to the repulsion between cations and $\mathrm{H}^{+}$ions with lower $\mathrm{pH}$. Conversely, at higher $\mathrm{pH}$ the negatively charged $\mathrm{OH}^{-}$attracts the cation of the dye and the negatively charged species (Figure 2a).

\subsubsection{Dye Concentration Influence}

The adsorption capacity of $\mathrm{CV}$ dye initial concentration has profound influence on NIFGS. The increase in the initial dye concentration from 25 to $300 \mathrm{mg} \mathrm{L}^{-1}$ onto NIFGS increased from 10 to $78 \mathrm{mg} \mathrm{g}^{-1}$. The adsorption of NIFGS related to the concentration gradient has a driving force on the dye adsorption (Figure $2 b$ ). The adsorption of $\mathrm{CV}$ was more with a higher concentration and reached almost constant after attaining equilibrium [37].

\subsubsection{Adsorbent Dosage Influence}

Adsorbent quantity has profound influence on the commercialization of the process because it decides the economic viability [38]. Adsorbent amount increment from 0.500 to $4.000 \mathrm{~g} \mathrm{~L}^{-1}$ is associated with reduced $\mathrm{CV}$ dye removal from the solution (Figure 2c). This observation assumes importance in the commercialization process where the number of trials with minimum amounts of the adsorbent substantially increases the dye removal efficiency of the dye by NIFGS. 


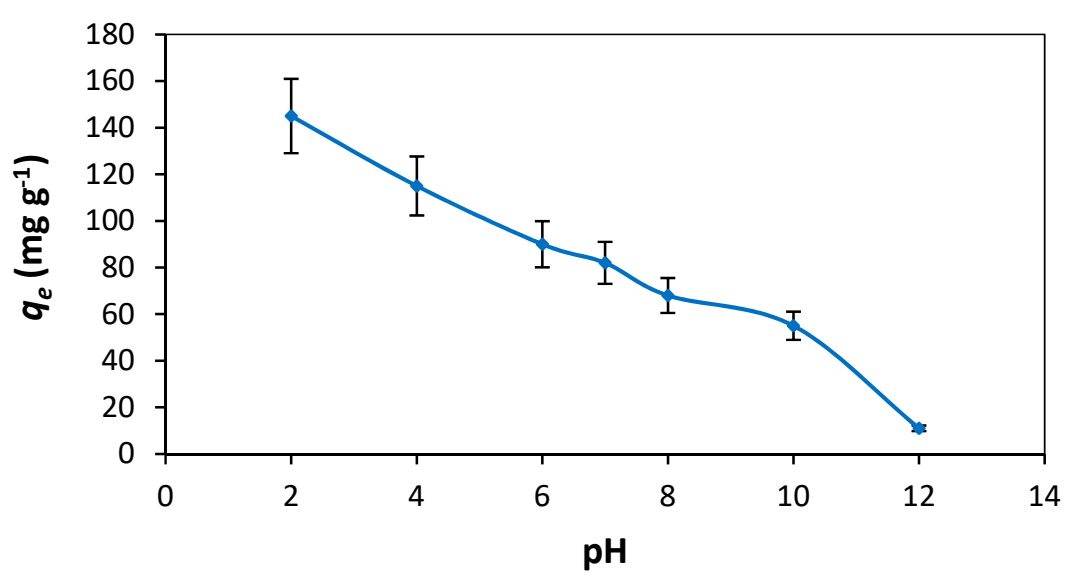

(a)

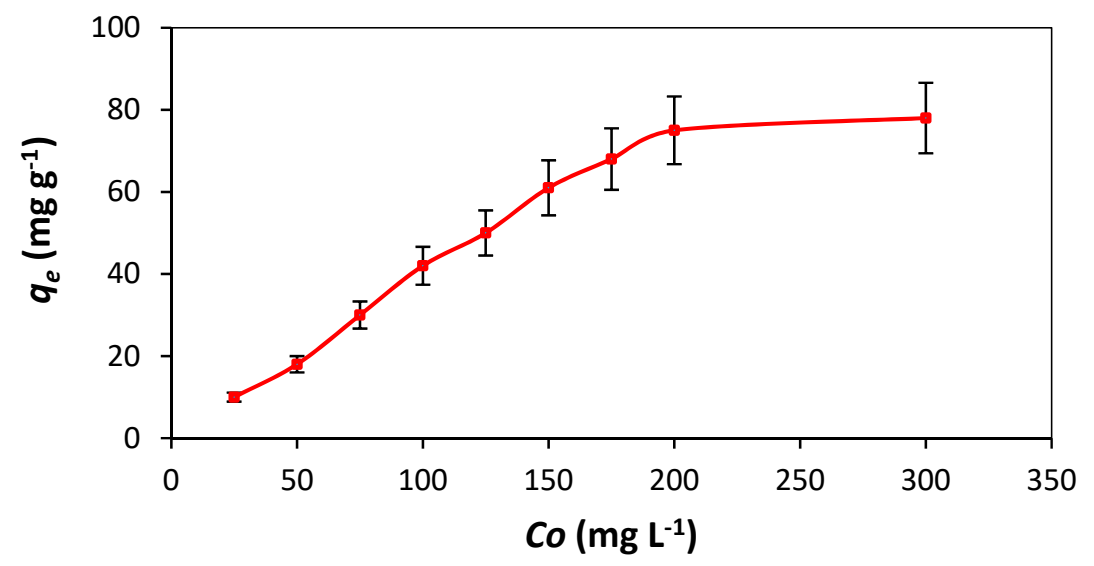

(b)

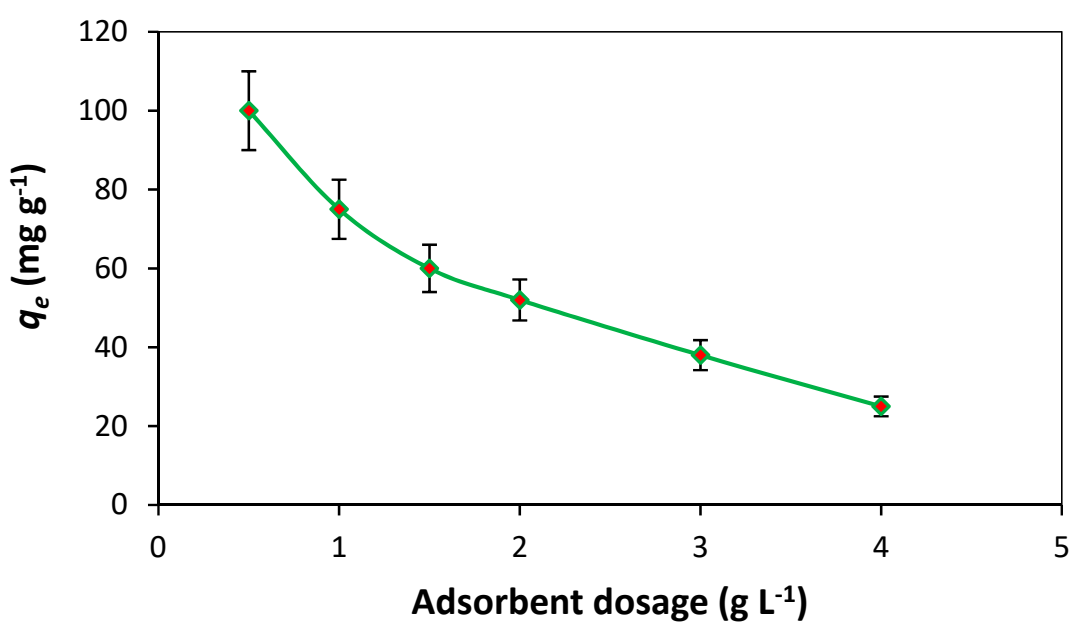

(c)

Figure 2. Cont. 


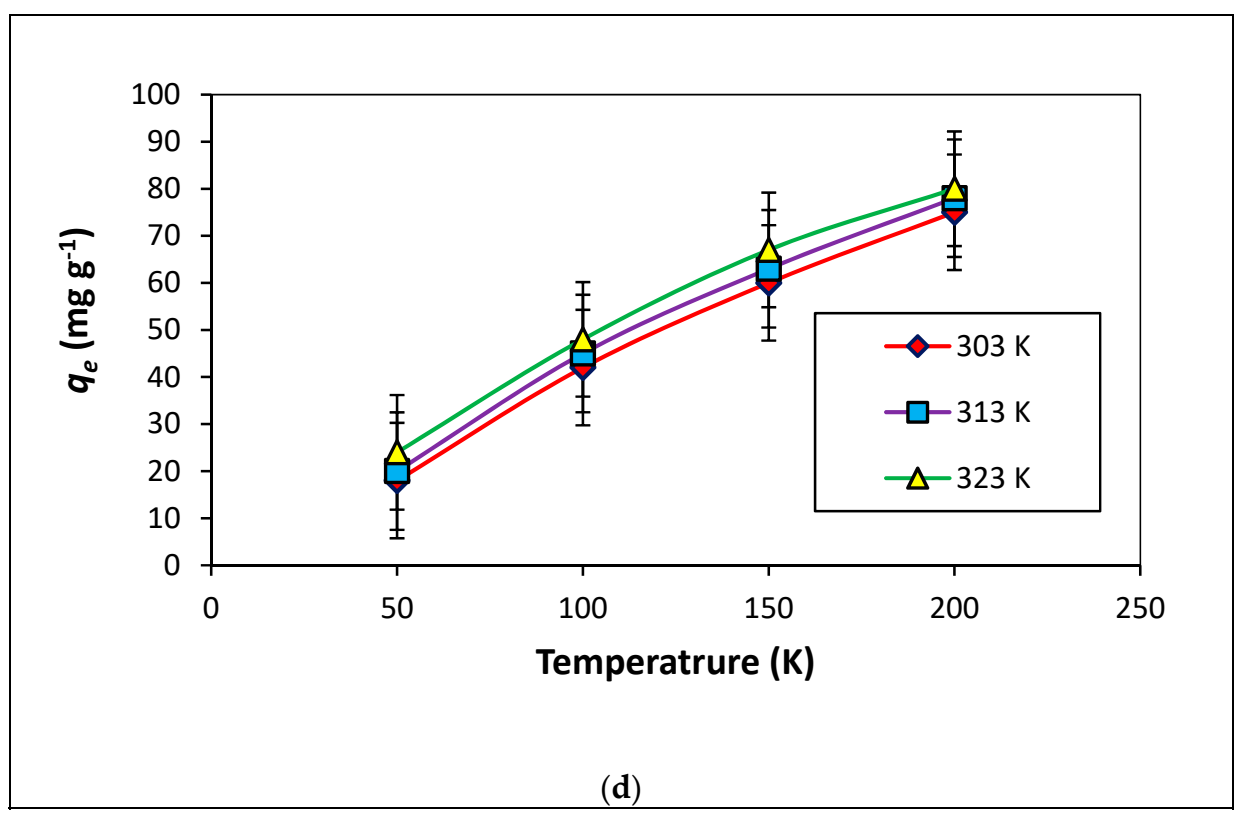

Figure 2. Effect on CV-NIFGS of: (a) $\mathrm{pH},(\mathbf{b})$ initial dye concentration, (c) adsorbent dosage and (d) temperature.

\subsubsection{Temperature Influence}

Keeping in view our focus to scale to commercial applications, evaluation of the process of adsorption of dyes onto NIFGS in relevance to thermal influence was studied. Temperature influence on CV dye adsorption onto NIFGS is presented in Figure $2 \mathrm{~d}$. The data obtained for the classical thermodynamic parameters, namely, $\Delta G^{\circ}, \Delta H^{\circ}$ and $\Delta S^{\circ}$ indicate the nature and type of reaction. For example, the positive $\Delta H^{\circ}$ (enthalpy) values obtained from 303 to $323 \mathrm{~K}$ of NIFGS indicate an endothermic process. The overall negative values of $\Delta G^{\circ}$ (free energy) obtained for CV-NIFGS system confirm the spontaneity and viability of adsorption. For spontaneous adsorption at reduced temperature, the extent of $\Delta G^{\circ}$ values indicates that the process of adsorption is rapid. Further, it is inferred that the positive $\Delta S^{\circ}$ value suggests more randomness at a solid solution interface and good affinity of CV towards the adsorbent. Similar observations were reported elsewhere [39].

The uncertainty principle, also known as Heisenberg's uncertainty principle, is a topic of quantum mechanics. Analytical chemists do not use this principle to determine the accuracy of the experiments carried out. Conversely, we report the accuracy in terms of the coefficient of variance which we incorporated in the text. The experiments which were carried out in our laboratory were performed in sets of three trials. The coefficients of variation in the results and uncertainty value for parametric influence such as $\mathrm{pH}$ grade of the solution, initial concentration of the dye, and the adsorbent quantity and temperature did not exceed $\pm 2 \%$ error. The error bars are incorporated for the Figures 2 and 3 respectively.

\subsection{Adsorption Isotherms-Modelling Analysis}

A study on the analysis of adsorption data using isotherm models (Langmuir and Freundlich) was intended for an efficiency evaluation of NIFGS in the extraction of CV dye for commercial applications with an eye on the degree of economic advantages. The main criterion of the study of adsorption isotherms was to select a model, where $q_{e}$ (the experimental equilibrium) values were almost equal to $Q_{m}$ (the monolayer adsorption capacity) value with a coefficient of determination $\left(R^{2}\right)$ value $\geq 0.90$. To refine the data and to make a distinction between the results obtained by two isotherm models, SSE and $\chi^{2}$ as two additional error functions were incorporated in our study. 

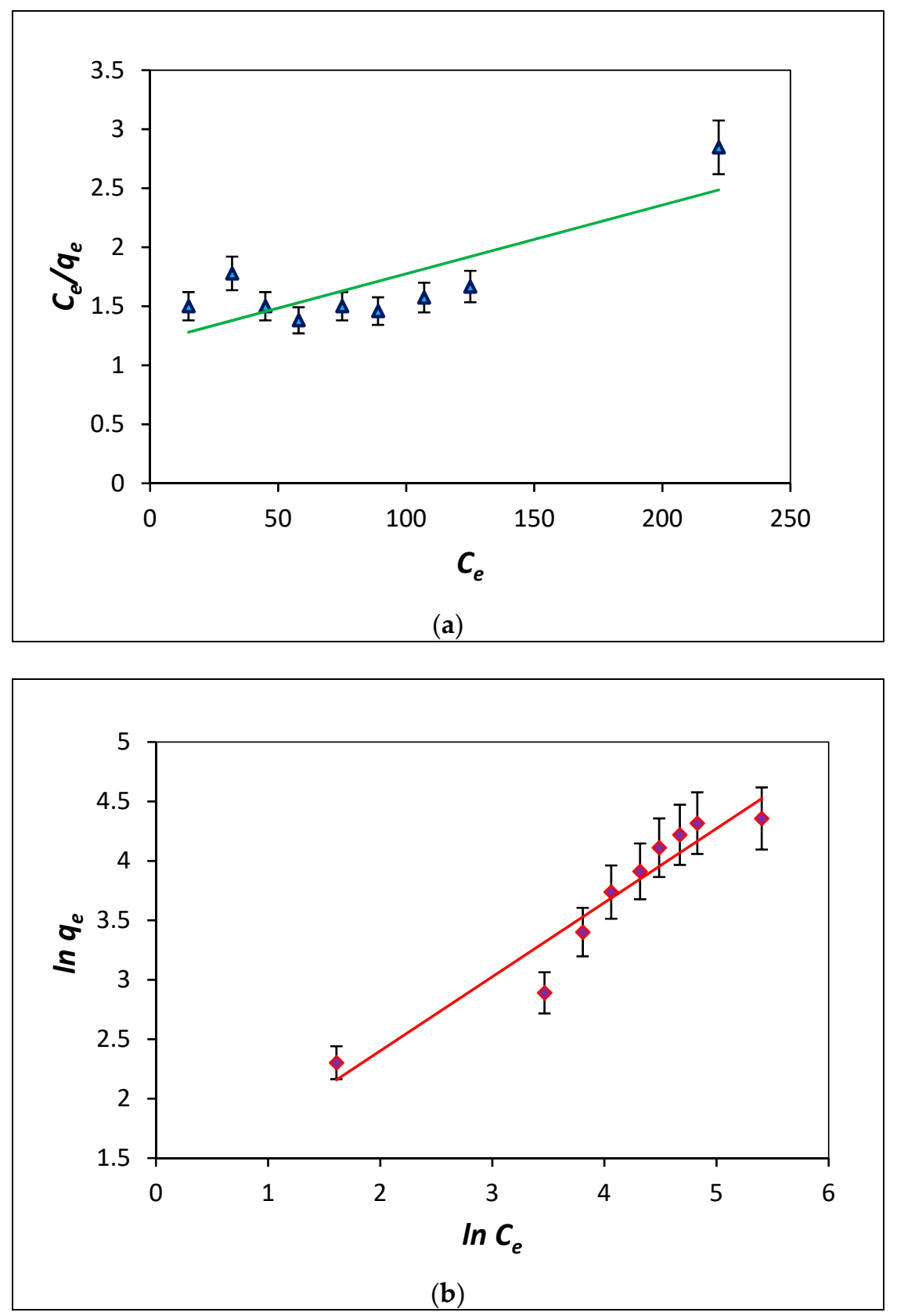

Figure 3. CV-NIFGS adsorption data fit to (a) Langmuir isotherm model and (b) Freundlich isotherm model.

Langmuir [30] proposed a model on the assumption that the adsorbent has active sites possessing almost uniform energies. This was further established on the idea that no lateral interaction takes place between adsorbed molecules. A plateau in a two-dimensional graph with equilibrium concentration $\left(C_{e}\right)$ as the independent variable and $q_{e}$ as the dependent variable characterizes that spontaneous surface sites of adsorbent are almost fully saturated. This implies that further adsorption cannot take place and the possibility of multilayer adsorption of the dye is ruled out. The equations of the Langmuir isotherm model are shown in Equations (4) and (5), Table 1. The Langmuir isotherm parameters, $\mathrm{q}_{\max }$ and $\mathrm{b}$ tabulation involves the slope $\left(1 / \mathrm{q}_{\max }\right)$ and intercept $\left(1 / \mathrm{bq}_{\max }\right)$ of the graph $C_{e} / q_{e}$ versus $C_{e}$ as shown in Figure 3a.

In contrast to the Langmuir isotherm model, Freundlich proposed the heterogeneity of the surface sites with different energy of adsorption and demonstrated relevance to multilayer adsorption [31]. The mathematical expression is shown in Equation (6), Table 1. 
A graph of $\ln \left(q_{e}\right)$ vs. $\ln \left(C_{e}\right)$ is utilised in calculation of the Freundlich constants $\mathrm{n}_{\mathrm{F}}$ (1.096) and $K_{F}$ (Figure $3 b$ ). The values suggest that the transfer of the dye from the bulk solution using NIFGS is physisorption and favours the Langmuir isotherm.

\subsection{Adsorption Kinetics}

The solute separation from solution adhering to adsorbent is known as adsorption which is dynamic in its nature. Kinetic models provide an insight on the performance of adsorption of CV dye on NIFGS with time as an independent variable. The studies will have a great impact on scaling for commercial applications. To provide the variation in adsorption rate, a concentration of 50,100 and $200 \mathrm{~g} \mathrm{~mL}^{-1}$ of CV dye was used to carry out kinetic studies at 303, 313 and $323 \mathrm{~K}$. Results are presented in Table 2. Kinetic data of adsorption of CV on NIFGS was analysed using the pseudo-first order model Equation (7), Table 1 [32] and pseudo-second order model Equation (8), Table 1 [33]. For the CV-NIFGS system the latter fits more appropriately than the other.

Table 2. Adsorption kinetics model predicted parameters.

\begin{tabular}{ccccccc}
\hline \multirow{2}{*}{$\begin{array}{c}\text { Initial } \\
\text { Concentration } \\
{\left[\mu \mathbf{g ~ m L}^{-\mathbf{1}}\right]}\end{array}$} & \multicolumn{3}{c}{ Pseudo-First Order } & \multicolumn{3}{c}{ Pseudo-Second Order } \\
\cline { 2 - 7 } & $\boldsymbol{q}_{\boldsymbol{e}}\left(\mathbf{m g ~ g}^{-\mathbf{1}}\right)$ & $\boldsymbol{K}_{\mathbf{1}}\left(\mathbf{m i n}^{-\mathbf{1}}\right)$ & $\boldsymbol{R}^{\mathbf{2}}$ & $\boldsymbol{q}_{\boldsymbol{e}}\left(\mathbf{m g ~ g}^{-\mathbf{1}}\right)$ & $\boldsymbol{K}_{\mathbf{1}}\left(\mathbf{m i n}^{-\mathbf{1}}\right)$ & $\boldsymbol{R}^{\mathbf{2}}$ \\
\hline 50 & 3.22 & 0.054 & 0.99 & 19.12 & 48.77 & 0.97 \\
\hline 100 & 4.52 & 0.045 & 0.98 & 44.24 & 237.25 & 0.98 \\
\hline
\end{tabular}

\subsection{Thermodynamics of the Adsorption Process}

Entropy $\left(\Delta S^{\circ}\right)$ and change in free energy $\left(\Delta G^{\circ}\right)$ in the dye-adsorbent system are main features of the process design of adsorption thermodynamics. The relationship of $\Delta G^{\circ}$, $\Delta H^{\circ}$ and $\Delta S^{\circ}$ are presented in Equations (9)-(12) (Table 1). The thermodynamic parameters were presented in Table 3 . The decrease in negative $\Delta G^{\circ}$ value with rise in temperature specifies the spontaneity of the adsorption process. The positive values of $\Delta S^{\circ}$ indicate the decrease in the randomness at the dye/NIFGS interface.

Table 3. CV-NIFGS thermodynamic factors.

\begin{tabular}{|c|c|c|c|c|}
\hline Dye Concentration & Temperature & $\begin{array}{c}\text { Change in Free } \\
\text { Energy } \\
\Delta G^{\circ}\end{array}$ & $\begin{array}{c}\text { Change in } \\
\text { Entropy } \\
\Delta S^{\circ}\end{array}$ & $\begin{array}{c}\text { Change in } \\
\text { Enthalpy } \\
\Delta H^{\circ}\end{array}$ \\
\hline \multirow[t]{2}{*}[\mu\mathrm{g}\mathrm{mL}^{-1}]{} & {$[\mathbf{K}]$} & {$[\mathrm{kJ} / \mathrm{mol}]$} & {$[\mathrm{J} / \mathrm{mol} \mathrm{K}]$} & {$[\mathrm{kJ} / \mathrm{mol}]$} \\
\hline & 303 & -2.52 & & \\
\hline \multirow[t]{2}{*}{50} & 313 & -2.65 & 23.28 & 9.91 \\
\hline & 323 & -2.77 & & \\
\hline \multirow{3}{*}{100} & 303 & -3.26 & & \\
\hline & 313 & -3.46 & 43.35 & 13.79 \\
\hline & 323 & -3.64 & & \\
\hline \multirow{3}{*}{200} & 303 & -4.07 & & \\
\hline & 313 & -4.29 & 63.28 & 17.82 \\
\hline & 323 & -4.53 & & \\
\hline
\end{tabular}




\subsection{Process Optimization}

The quadratic model in the fraction factorial experimental design (FEED) is used to statistically optimize the adsorption capacity under response surface methodology (RSM) $[40,41]$. The general equation of model can be explained:

$$
Y=\beta_{0}+\sum \beta_{i} X_{i}+\sum \beta_{i i} X^{2}+\sum \beta_{i j} X_{i} X_{j}
$$

where $Y$ is the response variable, $\beta_{0}$ is the coefficient of regression, $\beta_{i}$ is the linear influence, $\beta_{i i}$ is the quadratic influence and $\beta_{i j}$ is the variable $X$ interaction influence. The Design expert (7.0.0), statistical software was used for the RSM study, and the graphical representation of 3D and contour plots can be achieved for the response obtained for independent variables with an effect. The quadratic regression equation derived from the analysis of variance (ANOVA) shows the possible individual and combined effect of the factors for the CV-NIFGS system (Table 4). The $p$-value $<0.05 \%$ was considered significant with a $95 \%$ confidence interval.

Table 4. CV-NIFGS ANOVA table.

\begin{tabular}{cccccc}
\hline Sample & $\begin{array}{c}\text { Summation of } \\
\text { Squares }\end{array}$ & DoF & Square Mean & F-Value & $p$-Value \\
\hline Model & $13,547.2$ & 1 & $13,547.2$ & 103.2 & $<0.0001$ \\
\hline A & 113.6 & 1 & 113.6 & 0.9 & 0.3566 \\
\hline B & 717.6 & 1 & 717.6 & 5.5 & 0.0233 \\
\hline C & 1826.0 & 1 & 1826.0 & 13.9 & 0.0005 \\
\hline D & $10,862.6$ & 1 & $10,862.6$ & 82.7 & $<0.0001$ \\
\hline E & 878.9 & 1 & 878.9 & 6.7 & 0.0126 \\
\hline AC & 20.1 & 1 & 20.1 & 0.2 & 0.6972 \\
\hline BC & 1323.5 & 1 & 1323.5 & 10.1 & 0.0025 \\
\hline A $^{2}$ & 736.5 & 1 & 736.5 & 4.8 & 0.0322 \\
\hline B $^{2}$ & 100.7 & 1 & 100.7 & 0.7 & 0.4218 \\
\hline C $^{2}$ & 223.0 & 1 & 223.0 & 1.4 & 0.2333 \\
\hline $\mathrm{D}^{2}$ & 2437.6 & 1 & 2437.6 & 15.8 & 0.0002 \\
\hline $\mathrm{E}^{2}$ & 494.3 & 1 & 494.3 & 3.2 & 0.0777 \\
\hline Residual & 6695.6 & 51 & 131.3 & & \\
\hline Lack of fit & 5782.9 & 49 & 118.0 & 0.3 & 0.9724 \\
\hline Total & $54,053.8$ & 63 & & & \\
\hline
\end{tabular}

The regression equation obtained for CV-NIFGS system is shown below:

$$
\begin{gathered}
\text { CV-NIFGS }=36.14+28.10^{*} \mathrm{~A}-3.52^{*} \mathrm{~B}+19.15^{*} \mathrm{C}-21.21^{*} \mathrm{D} 62.29^{*} \mathrm{E}+11.92^{*} \mathrm{AC}+ \\
2.91^{*} \mathrm{BC} 20.29^{*} \mathrm{~A} 2+12.54^{*} \mathrm{~B} 2-35.16^{*} \mathrm{C} 2+10.77^{*} \mathrm{D} 2+20.80^{*} \mathrm{E} 2
\end{gathered}
$$

The values of the regression coefficient direct the parametric influence on the adsorption capacity. Surface and contour graphs illustrate the combined influence on adsorption by two factors. Graphical representation of the obtained results is in Figure 4. The fit of the second-order polynomial equation suggests $\mathrm{A}, \mathrm{C}, \mathrm{D}, \mathrm{AC}$ and $\mathrm{CE}$ have maximum effects with the regression coefficient value of 0.978 , which revealed the interaction of parameters studied and predicted adsorption capacity of $184 \mathrm{mg} \mathrm{g}^{-1}$ with the following optimum values based on a multiple regression analysis and the FFED model: $\mathrm{pH}$ 2, NIFGS dosage of $0.03 \mathrm{~g} \mathrm{~L}^{-1}, 204 \mathrm{mg} \mathrm{L}^{-1}$ as initial dye concentration and $165 \mathrm{~min}$ as adsorption time. Based on these optimal values, the estimated adsorption capacity is $184 \mathrm{mg} / \mathrm{g}$. 

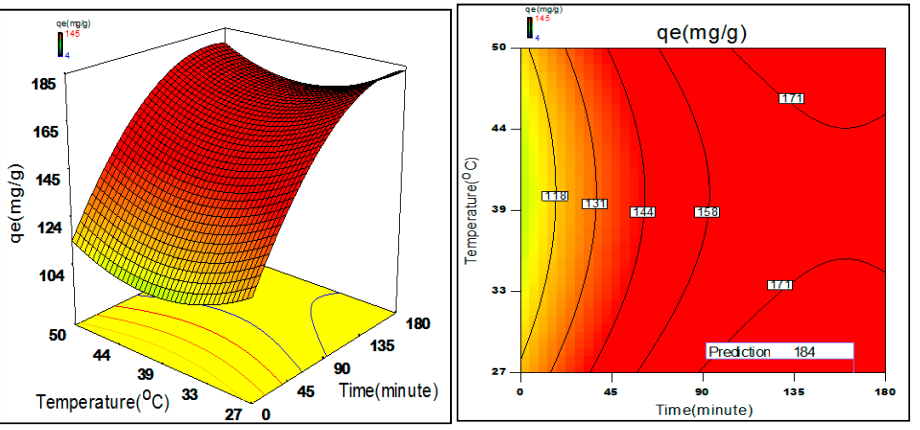

(a)
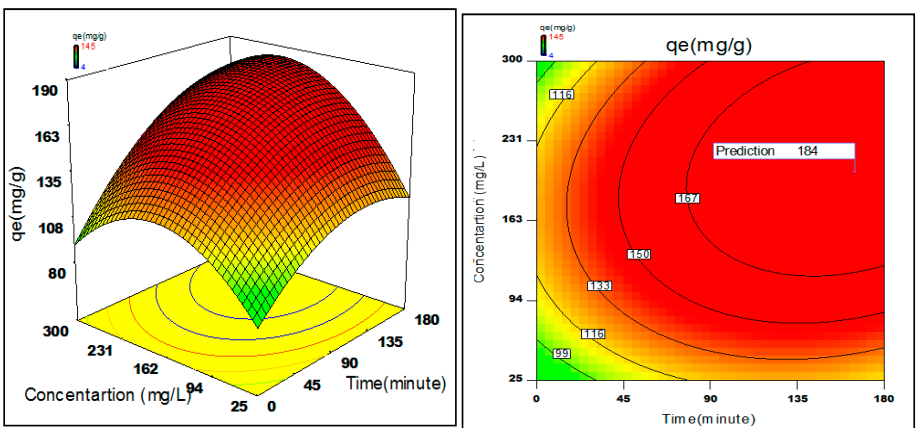

(b)
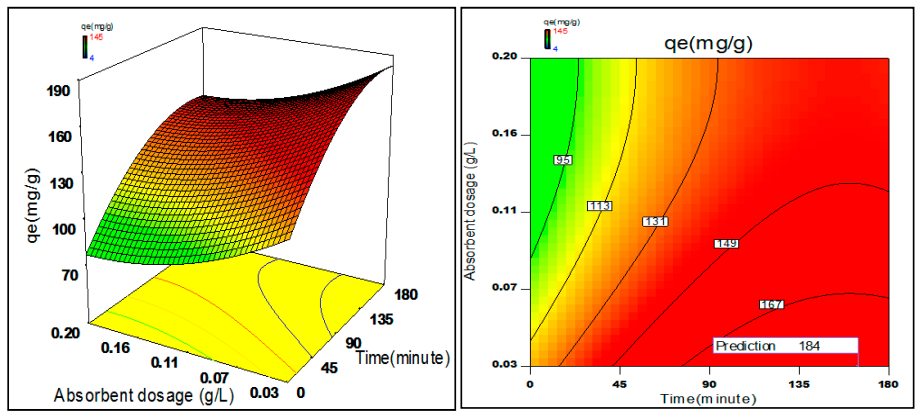

(c)

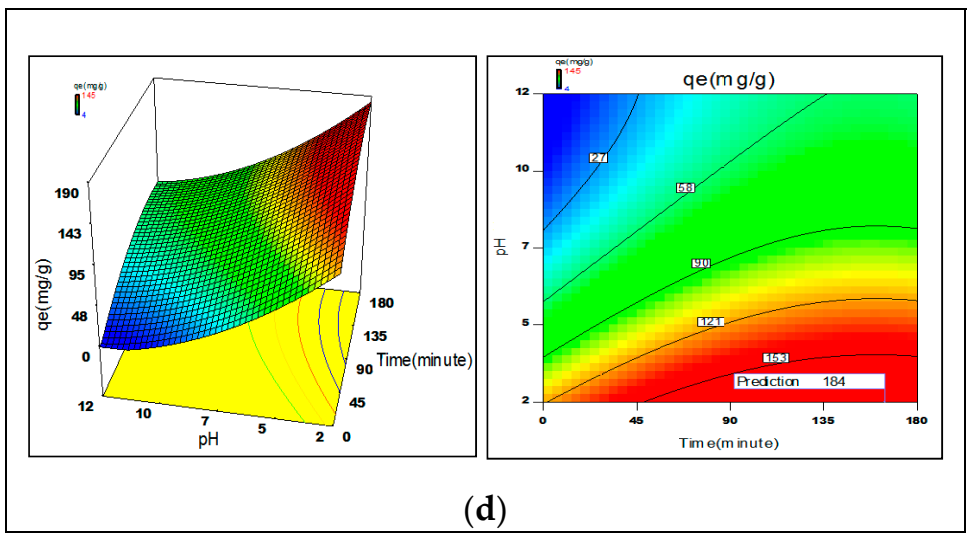

Figure 4. A 3D-surface plot and 2D-contour plot representing adsorption capacity variation relative to: (a) duration vs. temperature, (b) duration vs. concentration, (c) duration vs. adsorbent quantity and (d) duration vs. $\mathrm{pH}$. 
The effect of the interaction between two parameters and all other values are fixed and can be analysed by 3D response surface plots [42-47]. For example, the capacity increase in adsorption is noted at reduced $\mathrm{pH}$ grades and smaller NIFGS dosage. Significant effect on the dye adsorption was observed related to initial CV dye concentration. Similarly, adsorbent capacity to adsorb decreases with the increase in $\mathrm{pH}$.

\subsection{Mechanism of Adsorption}

The adsorbate, NIFGS, is a cellulosic material. The processes of the adsorption of CV dye onto cellulosic NIFGS comprises cellulose, hemicellulose and lignin. All the three materials invariably contain -OH groups. The plausible mechanism of cationic CV dye adsorption is likely to take place as follows:

- The progression of adsorption is a multistep activity;

- The factors that have credible influence on the process of adsorption are the solution acidic level $(\mathrm{pH})$, the concentration of dye, the amount of adsorbent used and variation in temperature;

- Monolayer is a formation initiated when the CV mass transfer occurs onto NIFGS;

- The process of diffusion is likely to be a slow process;

- The strong adherence of CV dye onto NIFGS is probably by bonds established between dye $\mathrm{N}^{+}$anions and hydrogen of cellulosic-OH group;

- Weak interaction is due to Van der Waals forces of attraction and strong electrostatic forces of attraction is because the $-\mathrm{N}^{+}$cationic group and the $-\mathrm{OH}^{+}$group negative charge of NIFGS contribute substantially to the adherence of the dye onto NIFGS.

\subsection{Optimized Condition}

3.8.1. Studies on Composites

Preparation of CV Dye-Adsorbed NIFGS

At total of $100 \mathrm{~g}$ of commercial CV dye was transferred to a $100 \mathrm{~L}$ barrel. The dye was dissolved in $25 \mathrm{~L}$ of TIE. A total of $5 \mathrm{Kg}$ of commercial NIFGS were transferred and the solution was stirred manually using a plastic rod. The solution was kept for about $24 \mathrm{~h}$ with occasional stirring. The dye-adsorbed NIFGS was separated using a cloth and the precipitate was washed thoroughly with distilled water until the filtrate was almost colourless. The blue colour dye-adsorbed NIFGS was air dried. The resultant powder containing lumps were grinded and sieved through $177 \mu \mathrm{m}$ mesh and dried in an oven at $60{ }^{\circ} \mathrm{C}$ for $24 \mathrm{~h}$. The powder was cooled in a closed container with an airtight lid. CV dye-adsorbed NIFGS was referred to as dye-modified NIFGS powder (dmNIFGS).

\section{Preparation of the Composites}

The composites of high-density polyethylene/dye-modified nutraceutical industrial fenugreek seed spent (HDPE/dmNIFGS) were prepared in two stages; dry-blending of HDPE resin with different proportions of dmNIFGS in a tumble mixer and melt compounding of master batches. HDPE granules and/or recycled product and dmNIFGS master batch flakes were compounded using a twin-screw extruder. The specimens were prepared by cutting the extrudate strands into pellets and were tested for physico-mechanical and chemical properties. The results were encouraging. The details will be reported elsewhere.

\section{Conclusions}

The present research states the NIFGS implementation to amputate cations crystal violet dye from aqueous solution and textile industrial effluent. The observations made admit that NIFGS is an efficient, cost-effective and eco-friendly adsorbent. The experimental equilibrium $\left(q_{e}\right)$ values of $184.00 \mathrm{mg} / \mathrm{g}$ at $\mathrm{pH}$ value 2 and $82.00 \mathrm{mg} / \mathrm{g}$ at almost a neutral $\mathrm{pH}$ is quite encouraging to commercialize the process. Modelling analysis suggests the transfer of the dye from a bulk solution using NIFGS. The results categorise the process as physisorption compatible with the Langmuir isotherm. Adsorption followed the pseudosecond order model and reported as thermodynamically favourable. The process was 
observed to be spontaneous and feasible which commemorates the endothermic nature. The value of $p<0.001$ projects the significance of $\mathrm{pH}$ and the contact duration for efficient $\mathrm{CV}$ adsorption onto an adsorbent surface. The dye-modified NIFGS has potential as a reinforcing material for the fabrication of composites using plastic waste.

In brief, the study has relevance to three industrial sectors, namely: textile industries, nutraceutical industries and plastic industries. The industrial production has a linear model to create value in making the product and completes the life cycle with disposal after use. This model seriously affects the environment and ecology due to the unprecedented problem of resource depletion. To address the issue of resource depletion there is a need from the industries to shift from virgin inputs to recycled and/or reused products. This study is a step towards this goal.

Author Contributions: Conceptualization, S.N.T., M.E.M.S. and M.C.S.; Methodology, S.N.T., M.C.S. and B.A.K.; Investigation, S.N.T. and M.E.M.S.; Resources, S.N.T., M.C. and B.A.K.; Writing-original draft preparation, M.R.S. and M.S.G.; Writing-review and editing, I.B.K.; Review and editing, M.I.H.S., M.A.A. and Z.S.; Project Administration, M.R.S.; Supervision, M.R.S. and M.E.M.S.; Funding, M.A.E. and C.A.S.; Research Support, A.S.K.; Support, Review and Editing, A.E. All authors have read and agreed to the published version of the manuscript.

Funding: King Khalid University, Saudi Arabia, Research Group Program under grant no. RGP.2/108/ 42. Taif University researchers supporting project number (TURSP-2020/123), Taif University, Taif, Saudi Arabia.

Institutional Review Board Statement: Not Applicable.

Informed Consent Statement: Not Applicable.

Data Availability Statement: Not Applicable.

Acknowledgments: The authors extend their appreciation to the Deanship of Scientific Research at King Khalid University, Saudi Arabia for funding this work through General Research Group Program under Grant No: RGP. 2/108/42. This work was supported by Taif University researchers supporting project number (TURSP-2020/123), Taif University, Taif, Saudi Arabia.

Conflicts of Interest: The authors declare no conflict of interest.

\section{References}

1. Indian Brand Equity Foundation. Textile Industry \& Market Growth in India. Available online: https:/ /www.fibre2fashion.com/ industry-article/2363/indian-textile-industry-an-overview (accessed on 22 January 2021).

2. Indian Brand Equity Foundation. Indian Textiles and Apparel Industry. Available online: https://www.ibef.org/industry/ textiles.aspx (accessed on 28 March 2021).

3. The World's Most Polluting Industries. Available online: https://www.worldatlas.com/articles/the-top-10-polluting-industriesin-the-world.html (accessed on 23 November 2020).

4. Wu, G.H.; Wu, X.Y.; Wang, L.; Liu, S.Q.; Ding, X.; Cuc, S. Water footprint and carbon footprint reduction in textile's waste recycling. Redactie 2015, 66, 85 .

5. Verma, A.K.; Dash, R.R.; Bhunia, P. A review on chemical coagulation/flocculation technologies for removal of colour from textile wastewaters. J. Environ. Manag. 2012, 4, 154-168. [CrossRef] [PubMed]

6. Yadav, A.A.; Kang, S.W.; Hunge, Y.M. Photocatalytic degradation of Rhodamine B using graphitic carbon nitride photocatalyst. J. Mater. Sci. Mater. Electron. 2021, 4, 15577-15585. [CrossRef]

7. Hunge, Y.M.; Yadav, A.A.; Khan, S.; Takagi, K.; Suzuki, N.; Teshima, K.; Terashima, C.; Fujishima, A. Photocatalytic degradation of bisphenolA using titanium dioxide@ nanodiamond composites under UV light illumination. J. Colloid Interface Sci. 2021, 4, 1058-1066. [CrossRef]

8. Sarafraz, M.M.; Tian, Z.; Tlili, I.; Kazi, S.; Goodarzi, M. Thermal evaluation of a heat pipe working with n-pentane-acetone and n-pentane-methanol binary mixtures. J. Therm. Anal. Calorim. 2020, 4, 2435-2445. [CrossRef]

9. Sarafraz, M.M.; Safaei, M.R.; Goodarzi, M.; Arjomandi, M. Reforming of methanol with steam in a micro-reactor with $\mathrm{Cu}-\mathrm{SiO}_{2}$ porous catalyst. Int. J. Hydrogen Energy 2019, 4, 19628-19639. [CrossRef]

10. Sarafraz, M.M.; Safaei, M.R.; Goodarzi, M.; Arjomandi, M. Experimental investigation and performance optimisation of a catalytic reforming micro-reactor using response surface methodology. Energy Convers. Manag. 2019, 4, 111983. [CrossRef]

11. Sarafraz, M.M.; Safaei, M.R. Diurnal thermal evaluation of an evacuated tube solar collector (ETSC) charged with graphenenanoplatelets-methanol nano-suspension. Renew. Energy 2019, 4, 364-372. [CrossRef] 
12. Sarafraz, M.M.; Arya, H.; Saeedi, M.; Ahmadi, D. Flow boiling heat transfer to MgO-therminol 66 heat transfer fluid: Experimental assessment and correlation development. Appl. Therm. Eng. 2018, 4, 552-562. [CrossRef]

13. Bagherzadeh, S.A.; Jalali, E.; Sarafraz, M.M.; Akbari, O.A.; Karimipour, A.; Goodarzi, M.; Bach, Q.V. Effects of magnetic field on micro cross jet injection of dispersed nanoparticles in a microchannel. Int. J. Numer. Methods Heat Fluid Flow 2019, 4, $2683-2704$. [CrossRef]

14. Sarafraz, M.M.; Kiani, T.; Hormozi, F. Critical heat flux and pool boiling heat transfer analysis of synthesized zirconia aqueous nano-fluids. Int. Commun. Heat Mass Transf. 2016, 4, 75-83. [CrossRef]

15. Peyghambarzadeh, S.M.; Sarafraz, M.M.; Vaeli, N.; Ameri, E.; Vatani, A.; Jamialahmadi, M. Forced convective and subcooled flow boiling heat transfer to pure water and n-heptane in an annular heat exchanger. Ann. Nucl. Energy 2013, 4, 401-410. [CrossRef]

16. Li, Z.X.; Khaled, U.; Al-Rashed, A.A.; Goodarzi, M.; Sarafraz, M.M.; Meer, R. Heat transfer evaluation of a micro heat exchanger cooling with spherical carbon-acetone nanofluid. Int. J. Heat Mass Transf. 2020, 4, 119124. [CrossRef]

17. Sarafraz, M.M.; Safaei, M.R.; Leon, A.S.; Tlili, I.; Alkanhal, T.A.; Tian, Z.; Goodarzi, M.; Arjomandi, M. Experimental investigation on thermal performance of a PV/T-PCM (photovoltaic/thermal) system cooling with a PCM and nanofluid. Energies 2019, 4, 2572. [CrossRef]

18. Kale, V.; Hunge, Y.M.; Kamble, S.A.; Deshmukh, M.; Bhoraskar, S.V.; Mathe, V.L. Modification of energy level diagram of nano-crystalline $\mathrm{ZnO}$ by its composites with $\mathrm{ZnWO}_{4}$ suitable for sunlight assisted photo catalytic activity. Mater. Today Commun. 2021, 4, 102101. [CrossRef]

19. Hunge, Y.M.; Yadav, A.A.; Kang, S.W.; Kim, H.; Fujishima, A.; Terashima, C. Nanoflakes-like nickel cobaltite as active electrode material for 4-nitrophenol reduction and supercapacitor applications. J. Hazard. Mater. 2021, 4, 126453. [CrossRef]

20. Yadav, A.A.; Hunge, Y.M.; Kang, S.W. Porous nanoplate-like tungsten trioxide/reduced graphene oxide catalyst for sonocatalytic degradation and photocatalytic hydrogen production. Surf. Interfaces 2021, 4, 101075. [CrossRef]

21. Dávila-Jiménez, M.M.; Elizalde-González, M.P.; Peláez-Cid, A.A. Adsorption interaction between natural adsorbents and textile dyes in aqueous solution. Colloids Surf. A Physicochem. Eng. Asp. 2005, 4, 107-114. [CrossRef]

22. Szyguła, A.; Guibal, E.; Ruiz, M.; Sastre, A.M. The removal of sulphonated azo-dyes by coagulation with chitosan. Colloids Surf. A Physicochem. Eng. Asp. 2008, 4, 219-226. [CrossRef]

23. Taqui, S.N.; Yahya, R.; Hassan, A.; Nayak, N.; Syed, A.A. A novel sustainable design to develop polypropylene and unsaturated polyester resin polymer composites from waste of major polluting industries and investigation on their physicomechanical and wear properties. Polym. Compos. 2019, 4, 1142-1157. [CrossRef]

24. Yakuth, S.A.; Taqui, S.N.; Syed, U.T.; Syed, A.A. Nutraceutical industrial chillies stalk waste as a new adsorbent for the removal of Acid Violet 49 from water and textile industrial effluent: Adsorption isotherms and kinetic models. Desalin. Water Treat. 2019, 4, 94-112. [CrossRef]

25. Papegowda, P.K.; Syed, A.A. Isotherm, kinetic and thermodynamic studies on the removal of methylene blue dye from aqueous solution using saw palmetto spent. Int. J. Environ. Res. 2017, 11, 91-98. [CrossRef]

26. India Production of Horticulture Crops in India. CIEC. Available online: https://www.ceicdata.com/en/india/production-ofhorticulture-crops-inindia/production-horticulture-crops-spices (accessed on 23 November 2020).

27. Petropoulos, G.A. (Ed.) Fenugreek: The Genus Trigonella; CRC Press: Boca Raton, FL, USA, 2003.

28. Dhaif-Allah, M.A.; Taqui, S.N.; Syed, U.T.; Syed, A.A. Kinetic and isotherm modeling for acid blue 113 dye adsorption onto low-cost nutraceutical industrial fenugreek seed spent. Appl. Water Sci. 2020, 4, 1-16. [CrossRef]

29. Tahir, S.S.; Rauf, N. Removal of a cationic dye from aqueous solutions by adsorption onto bentonite clay. Chemosphere 2006, 4 , 1842-1848. [CrossRef]

30. Langmuir, I. The constitution and fundamental properties of solids and liquids. Part I Solids. J. Am. Chem. Soc. 1916, 4, 2221-2295. [CrossRef]

31. Freundlich, H.M.F. Over the adsorption in solution. J. Phys. Chem. 1906, 4, 385471.

32. Lagergren, S.K. About the theory of so-called adsorption of soluble substances. Sven. Vetenskapsakad. Handingarl 1898, 4, 1-39.

33. Ho, Y.S.; McKay, G. Sorption of dye from aqueous solution by peat. Chem. Eng. J. 1998, 4, 115-124. [CrossRef]

34. Taqui, S.N.; Yahya, R.; Hassan, A.; Nayak, N.; Syed, A.A. Adsorption of Acid Blue 113 from aqueous solution onto nutraceutical industrial coriander seed spent: Isotherm, kinetics, thermodynamics and modeling studies. Desalin. Water Treat. 2019, 4, 321-337. [CrossRef]

35. Taqui, S.N.; Yahya, R.; Hassan, A.; Nayak, N.; Syed, A.A. Valorization of Nutraceutical Industrial Coriander Seed Spent by the Process of Sustainable Adsorption System of Acid Black 52 from Aqueous Solution. Int. J. Environ. Res. 2019, 13, 639-659. [CrossRef]

36. Childress, A.E.; Elimelech, M. Effect of solution chemistry on the surface charge of polymeric reverse osmosis and nanofiltration membranes. J. Membr. Sci. 1996, 4, 253-268. [CrossRef]

37. Sulthana, R.; Taqui, S.N.; Zameer, F.; Syed, U.T.; Syed, A.A. Adsorption of ethidium bromide from aqueous solution onto nutraceutical industrial fennel seed spent: Kinetics and thermodynamics modeling studies. Int. J. Phytoremediat. 2018, 4, 1075-1086. [CrossRef]

38. Taqui, S.N.; Yahya, R.; Hassan, A.; Nayak, N.; Syed, A.A. Development of sustainable dye adsorption system using nutraceutical industrial fennel seed spent-Studies using Congo red dye. Int. J. Phytoremediat. 2017, 4, 686-694. [CrossRef] 
39. Alkan, M.; Demirbaş, Ö.; Doğan, M. Adsorption kinetics and thermodynamics of an anionic dye onto sepiolite. Microporous Mesoporous Mater. 2007, 4, 388-396. [CrossRef]

40. Dhaif-Allah, M.A.H.; Taqui, S.N.; Syed, U.T.; Syed, A.A. Development of sustainable acid blue 113 dye adsorption system using nutraceutical industrial Tribulus terrestris spent. SN Appl. Sci. 2019, 1, 330. [CrossRef]

41. Peng, Y.; Khaled, U.; Al-Rashed, A.A.; Meer, R.; Goodarzi, M.; Sarafraz, M.M. Potential application of Response Surface Methodology (RSM) for the prediction and optimization of thermal conductivity of aqueous CuO (II) nanofluid: A statistical approach and experimental validation. Phys. A Stat. Mech. Its Appl. 2020, 4, 124353. [CrossRef]

42. Hosseini, S.M.; Safaei, M.R.; Goodarzi, M.; Alrashed, A.A.; Nguyen, T.K. New temperature, interfacial shell dependent dimensionless model for thermal conductivity of nanofluids. Int. J. Heat Mass Transf. 2017, 114, 207-210. [CrossRef]

43. Bagherzadeh, S.A.; D'Orazio, A.; Karimipour, A.; Goodarzi, M.; Bach, Q.V. A novel sensitivity analysis model of EANN for F-MWCNTs- $\mathrm{Fe}_{3} \mathrm{O}_{4} /$ EG nanofluid thermal conductivity: Outputs predicted analytically instead of numerically to more accuracy and less costs. Phys. A Stat. Mech. Its Appl. 2019, 4, 406-415. [CrossRef]

44. Ahmadi, A.A.; Arabbeiki, M.; Ali, H.M.; Goodarzi, M.; Safaei, M.R. Configuration and optimization of a minichannel using water-alumina nanofluid by non-dominated sorting genetic algorithm and response surface method. Nanomaterials $2020,4,901$. [CrossRef]

45. Peng, Y.; Parsian, A.; Khodadadi, H.; Akbari, M.; Ghani, K.; Goodarzi, M.; Bach, Q.V. Develop optimal network topology of artificial neural network (AONN) to predict the hybrid nanofluids thermal conductivity according to the empirical data of $\mathrm{Al}_{2} \mathrm{O}_{3}-\mathrm{Cu}$ nanoparticles dispersed in ethylene glycol. Phys. A Stat. Mech. Its Appl. 2020, 4, 124015. [CrossRef]

46. Ahmadi, M.H.; Mohseni-Gharyehsafa, B.; Ghazvini, M.; Goodarzi, M.; Jilte, R.D.; Kumar, R. Comparing various machine learning approaches in modeling the dynamic viscosity of $\mathrm{CuO} /$ water nanofluid. J. Therm. Anal. Calorim. 2020, 4, 2585-2599. [CrossRef]

47. Giwa, S.O.; Sharifpur, M.; Goodarzi, M.; Alsulami, H.; Meyer, J.P. Influence of base fluid, temperature, and concentration on the thermophysical properties of hybrid nanofluids of alumina-ferrofluid: Experimental data, modeling through enhanced ANN, ANFIS, and curve fitting. J. Therm. Anal. Calorim. 2021, 143, 4149-4167. [CrossRef] 